\title{
Small Punch Test Application to Material Properties Evolution Determination*
}

\author{
Jan DŽUGAN** and Pavel KONOPÍK** \\ ${ }^{* *}$ COMTES FHT Inc. \\ Prumyslova 995, 33441 Dobrany, The Czech Republic \\ E-mail: jan.dzugan@comtesfht.cz
}

\begin{abstract}
The current paper deals with the ability of the Small Punch Test [SPT] to detect material behaviour changes. The authors investigated two experimental materials with a range of mechanical properties. The different material properties of the experimental materials were obtained by heat treatment, simulating material property changes due to service conditions. The ability of SPT to detect such changes was investigated on the basis of tensile and fracture toughness properties. In order to be able to perform such an investigation, standard tensile tests and fracture toughness tests were performed for reference. A wide range of tensile strengths, ranging from 700 to $2000 \mathrm{MPa}$, and fracture toughness values covering the brittle-to-ductile region from 90 to $350 \mathrm{MPa} \cdot \mathrm{m}^{0,5}$ were utilized for the method sensitivity assessment. The results of standard tests are compared with SPT results and their applicability is evaluated.
\end{abstract}

Key words: Small Punch Test, Fracture Toughness, Brittle Fracture, Ductile Fracture, Tensile Test

\section{Introduction}

There are increasing demands for the integrity assessment of important structures over the course of their service life. Fracture mechanics has attained high significance in establishing the ultimate load limitations and in assessing the integrity of many engineering structures of multifarious types. The fracture mechanics-based integrity assessment procedure for components requires fracture toughness properties of the materials which in many cases are difficult to obtain, due to lack of experimental material. For this reason non-destructive techniques are being developed, as well as testing methods using mini-samples to enable conversion of test results into conventional parameters such as tensile properties and fracture toughness parameters. One of the methods of the highest interest is the Small Punch Test (SPT).

The SPT method uses small disc-shaped samples with usual dimensions of $8 \mathrm{~mm}$ diameter and $0.5 \mathrm{~mm}$ thickness. The test itself is a very simple penetration of a hard ball into the test sample while the applied force and ball displacement are measured, either at room temperature or at non-ambient temperature. But problems may arise in the evaluation of the tests. Many procedures have been proposed for correlations between SPT and a variety of mechanical test results including tensile, Charpy impact, transition temperature determinations, fracture toughness evaluation, etc.

Some proposed correlations of SPT with tensile test properties and fracture toughness are given in publications [1-10]. These correlations are not generally valid for all materials: therefore in the current paper the correlations are re-assessed and directly applied to the

${ }^{*}$ Received 1 Dec., 2011 (№. 11-0746) [DOl: 10.1299/jmmp.6.782]

Copyright $@ 2012$ by JSME 
materials investigated. Hence the performance of SPT for conventional properties evaluation is evaluated.

\section{Experimental Materials}

The experimental materials used were two steels. The first is an experimental grade of low carbon steel, designated as Steel 1. The second is Czech Standard grade 16343 (whose international equivalent is $34 \mathrm{CrNiMo6}$ ). Steel 1 was investigated in six different states (as-received, and annealed at 250,350, 440, 500 and $620^{\circ} \mathrm{C}$ ) produced from one material block. Steel 16343 was tested in as-received condition exhibiting upper shelf behaviour at room temperature, and in the quenched state exhibiting brittle behaviour at room temperature. Tests on steel 16343 in the as-received condition were performed in both the longitudinal and transverse directions of the rolled bar. The material tensile properties are summarized in Table 1.

Table 1. Tensile properties

\begin{tabular}{|c|c|c|c|c|c|}
\hline \multirow{3}{*}{ Material } & \multirow{2}{*}{ State } & $\mathbf{R}_{\mathbf{p} 0,2} / \mathbf{R}_{\mathrm{eH}}$ & $\mathbf{R}_{\mathbf{m}}$ & $\mathbf{A}_{\mathbf{5}}$ & $\mathbf{Z}$ \\
\cline { 2 - 6 } & & {$[\mathrm{MPa}]$} & {$[\mathrm{MPa}]$} & {$[\%]$} & {$[\%]$} \\
\hline \multirow{5}{*}{ Steel 1 } & Original & 1144,8 & 1252,6 & 14,2 & 70,3 \\
\cline { 2 - 6 } & 250 & 1168,5 & 1365,6 & 13,6 & 67,1 \\
\cline { 2 - 6 } & 350 & 1166,6 & 1285,6 & 14,1 & 69,4 \\
\cline { 2 - 6 } & 440 & 981,1 & 1022,1 & 16,9 & 70,9 \\
\cline { 2 - 6 } & 500 & 816,0 & 863,3 & 17,5 & 71,2 \\
\hline \multirow{3}{*}{ 34CrNiMo6 } & 620 & 699,9 & 734,0 & 21,4 & 74,1 \\
\cline { 2 - 6 } & Longitudinal & 921,3 & 1050,4 & 17,5 & 63,4 \\
\cline { 2 - 6 } & Transversal & 952,6 & 1053,3 & 15,7 & 60,0 \\
\cline { 2 - 6 } & Quench & 1219,6 & 1965,0 & 10,7 & 38,8 \\
\hline
\end{tabular}

\section{Fracture toughness tests}

The fracture toughness tests were performed on three point bend specimens of thickness B $12.5 \mathrm{~mm}$. The crosshead speed during the tests was $2 \mathrm{~mm} / \mathrm{min}$. The evaluation was performed according to ASTM E1820. Samples were machined then fatigue pre-cracked with the final stress intensity factor of about $20 \mathrm{MPa} \cdot \mathrm{m}^{1 / 2}$. Test pieces were side-grooved after pre-cracking and subsequently tested using the multiple specimen method. Crack lengths after testing were measured by digital image processing and stress intensity factor or J-integral was determined. At least three samples were tested for each material state. Tests were performed at room temperature, and in the case of steel 1 in the as-received condition, tests at $-20^{\circ} \mathrm{C}$ were also performed. The results of the fracture toughness test are summarized in Table 2. Some results did not fulfill the E1820 requirements for sizeindependent fracture toughness: these tests are denoted as $\boldsymbol{J}_{Q} / \boldsymbol{K}_{\boldsymbol{Q}}$ in the results table. 
Table 2. Fracture toughness values

\begin{tabular}{|c|c|c|c|c|}
\hline Material & State & $\begin{array}{c}\text { Temperature } \\
{ }^{\circ} \mathbf{C}\end{array}$ & $\begin{array}{c}\mathrm{J}_{\mathrm{IC}}, \mathrm{J}_{\mathbf{Q}} \\
\mathrm{kN} \cdot \mathrm{m}\end{array}$ & $\begin{array}{c}\mathrm{K}_{\mathbf{I C}}, \mathrm{K}_{\mathbf{Q}} \\
\mathrm{MPa} \cdot \mathrm{m}^{0,5}\end{array}$ \\
\hline \multirow{5}{*}{ Steel 1 } & Original & 20 & ---- & 127,1 \\
\cline { 2 - 5 } & Original & -20 & ---- & 105,5 \\
\cline { 2 - 5 } & 250 & 20 & ---- & 112,6 \\
\cline { 2 - 5 } & 350 & 20 & ---- & 127,0 \\
\cline { 2 - 5 } & 440 & 20 & 253,5 & 241,9 \\
\cline { 2 - 5 } & 500 & 20 & 383,0 & 297,3 \\
\cline { 2 - 5 } & 620 & 20 & 517,0 & 345,4 \\
\hline \multirow{3}{*}{ 34CrNiMo6 } & Long & 20 & 286,8 & 257,3 \\
\cline { 2 - 5 } & Trans & 20 & 189,9 & 209,3 \\
\cline { 2 - 5 } & Quenched & 20 & 101,3 & 92,2 \\
\hline
\end{tabular}

\section{Small Punch Tests}

Small punch tests were performed in a servo-hydraulic testing system of $10 \mathrm{kN}$ capacity using the testing fixture shown to Fig. 1. Dimensions of the fixture can be found in Table 3.

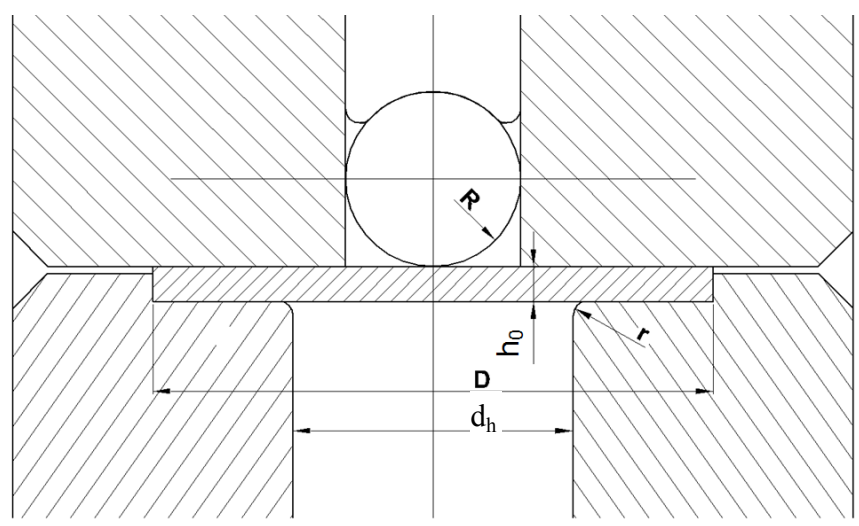

Fig. 1. Small punch test fixture

Table 3. Dimensions of SPT fixture

\begin{tabular}{|c|c|c|c|c|}
\hline$h_{0}$ & $D$ & $R$ & $r$ & $d_{h}$ \\
\hline 0,5 & 8,0 & 1,25 & 0,5 & 4,0 \\
\hline
\end{tabular}

The SPT sample preparation was as follows: first a disc of thickness about $1 \mathrm{~mm}$ was cut using coolant. Next the sample was ground from $1 \mathrm{~mm}$ thickness down to $0.6 \mathrm{~mm}$ on metallographic grinding discs while mounted in a specially-designed holder. The last $0.1 \mathrm{~mm}$ of sample thickness was removed by diamond polishing. During the preparation process the sample was regularly turned to ensure that both faces experienced similar cnditions. Tests were performed at room temperature and at $-20^{\circ} \mathrm{C}$. The tests at $-20^{\circ} \mathrm{C}$ were performed in a cooling chamber using liquid nitrogen vapour. The crosshead speed during SPT tests was $1 \mathrm{~mm} / \mathrm{min}$. Force-displacement curves obtained for all materials are shown in Figs. 2 and 3. 


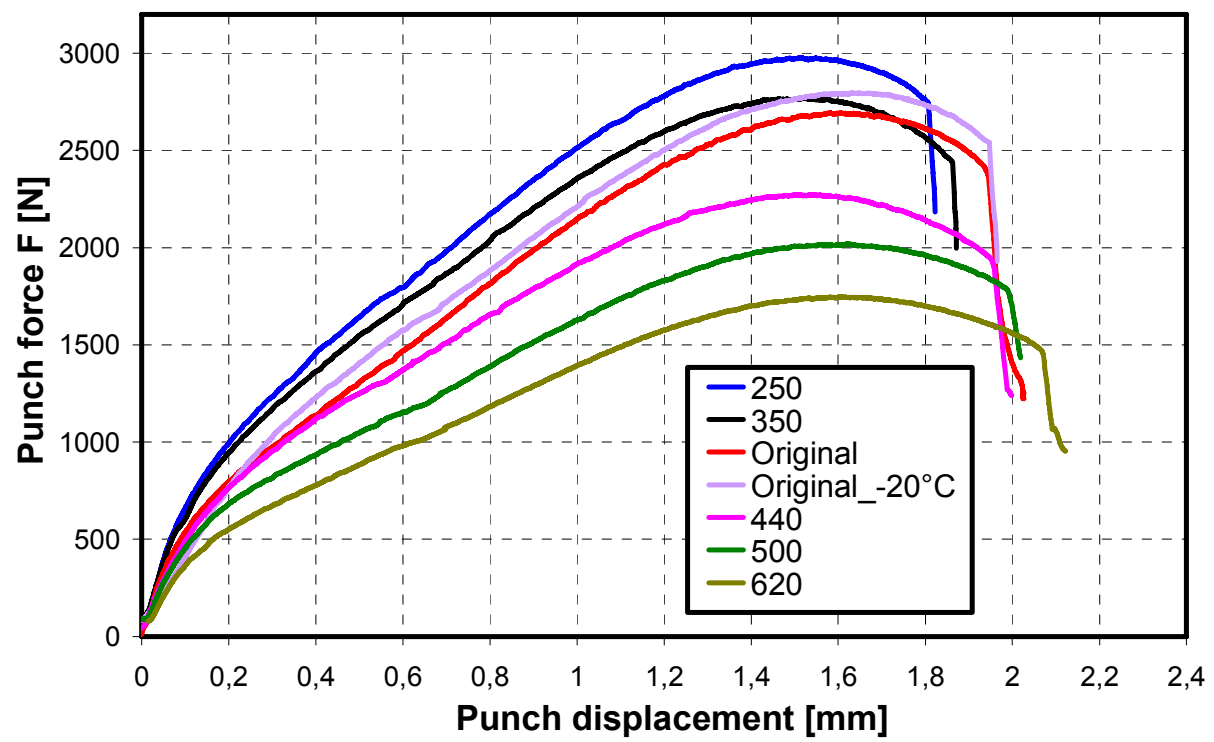

Fig. 2. SPT records - Steel 1

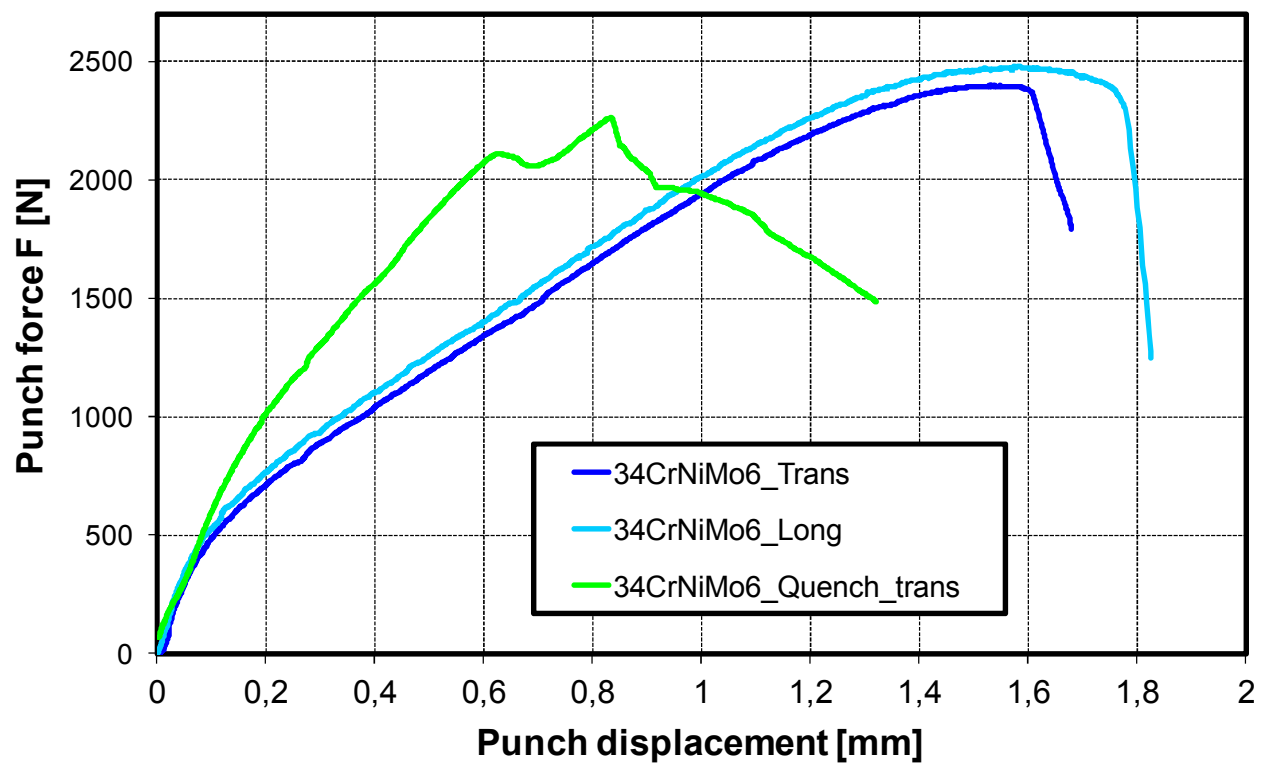

Fig. 3. SPT records - 34CrNiMo6

\section{SPT tests evaluation - tensile properties}

The records obtained were firstly used for the evaluation of the tensile properties of the materials investigated. To accomplish this, distinctive points from the records were determined according to Fig. 4 and subsequently the yield stresses and the tensile strengths were evaluated. Graphical reprsentions of the results obtained in comparison with standard tensile test results are shown in Figs. 5 and 6. It is clear that linear trends can be found for yield stress and tensile strength by comparison to tensile tests results. 


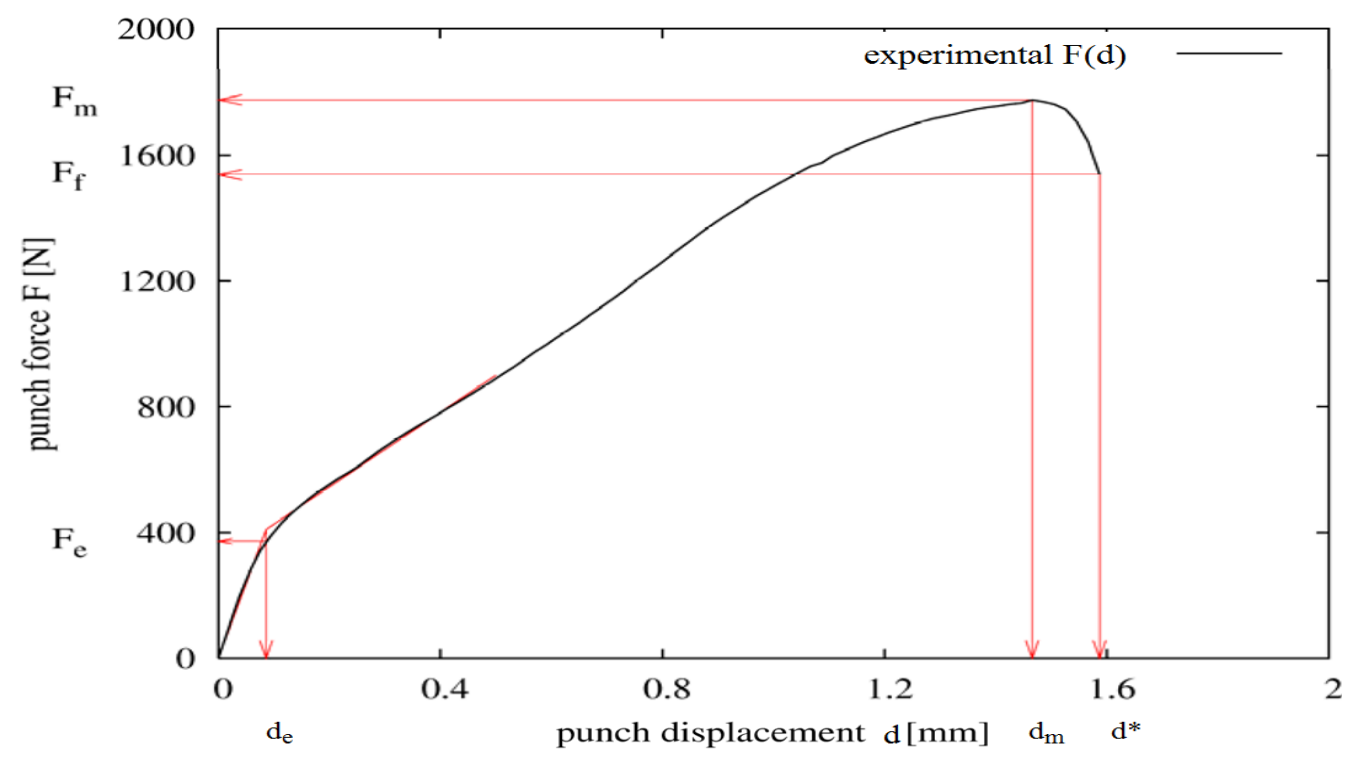

Fig. 4. Scheme of distinctive points determination from SPT record [5]

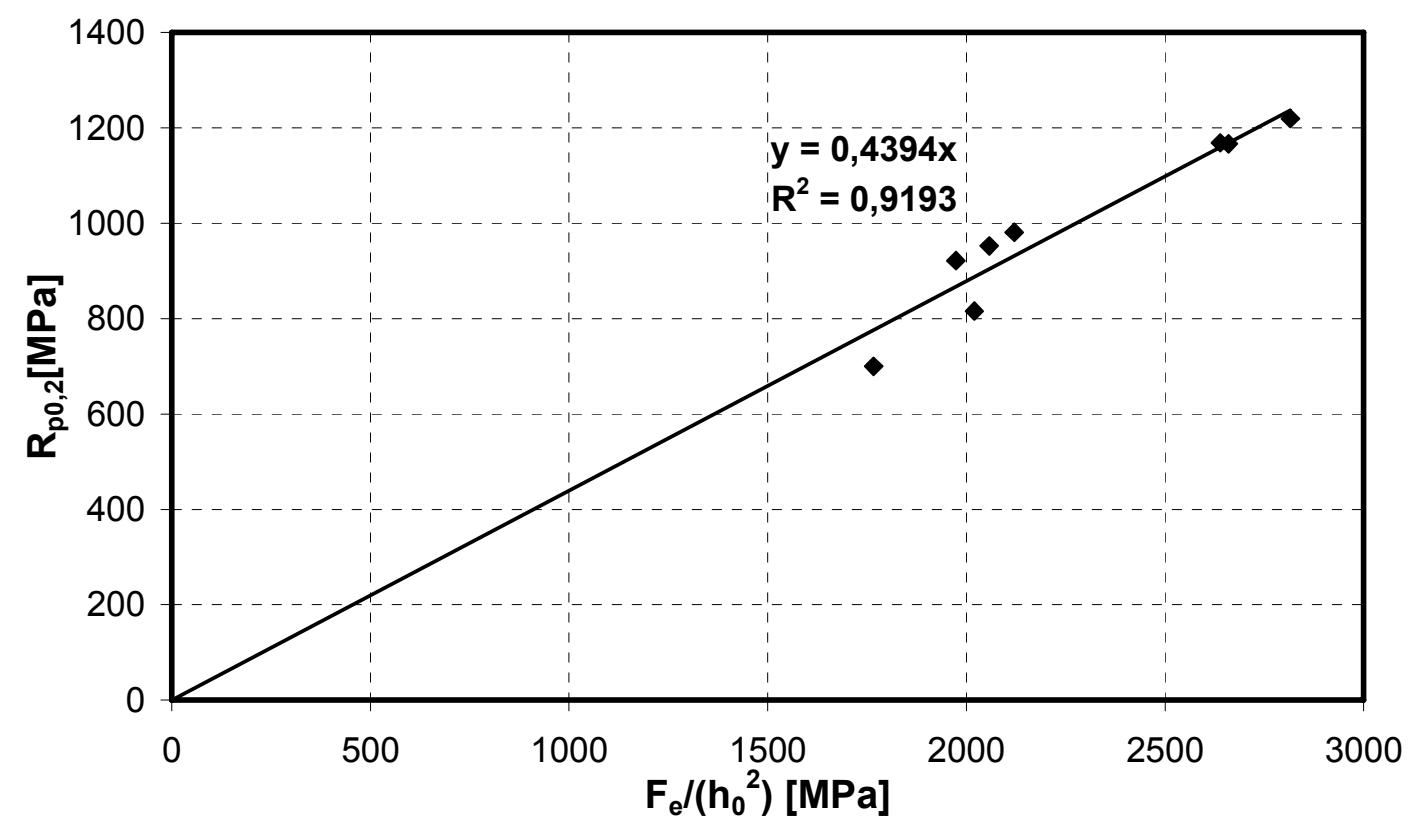

Fig. 5. Tensile Yield stress versus normalized $\boldsymbol{F}_{\boldsymbol{e}}$ from SPT 


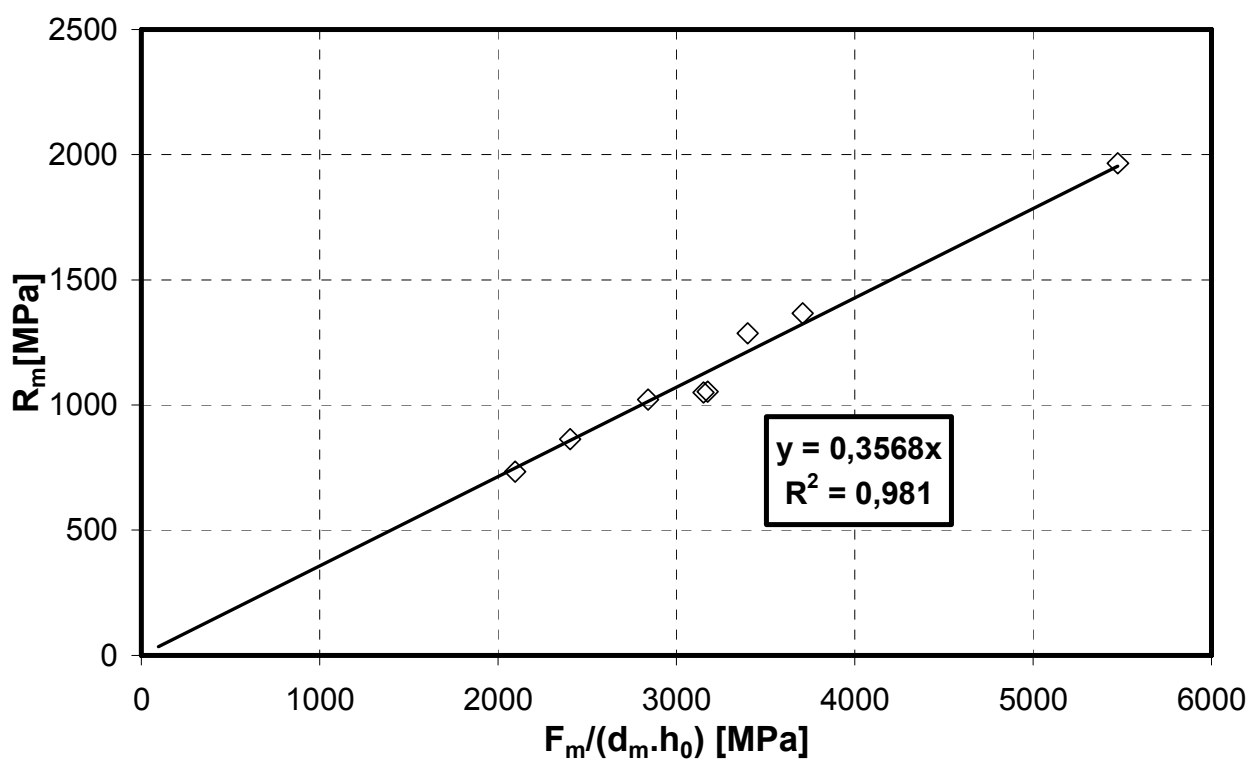

Fig. 6. Tensile strength versus normalized yielding force from SPT

Various procedures for fracture toughness evaluation from SPT have been published in [1-10]. In the case of brittle fracture the following relationship is recommended [3]:

$$
\begin{aligned}
& K_{I C}=C \cdot\left[\sigma_{f S P} l^{2 / 3}\right. \\
& \sigma_{f S P}=130\left(P_{\max } / h_{o}{ }^{2}\right)-320
\end{aligned}
$$

where $\boldsymbol{P}_{\boldsymbol{m a x}}$ is the force at unstable crack propagation and $\boldsymbol{h}_{\boldsymbol{0}}$ is the initial sample thickness. $\boldsymbol{C}$ is an empirically determined constant [5].

On the basis of the current results $C$ was determined to be 1.029. The results of fracture toughness evaluated with this constant were compared with fracture toughness data evaluated from standard tests, and the results are summarized in Table 4. A graphical representation of the obtained results is shown in Fig. 10.

In the case of upper shelf behaviour the following relation is widely used [5]:

$$
\begin{aligned}
& J_{I C}=K \cdot \varepsilon_{f}-J_{0} \\
& \varepsilon_{f}=\ln \left(h_{0} / h_{f}\right)=\beta \cdot\left(d^{*} / h_{0}\right)^{x}
\end{aligned}
$$

where $\varepsilon_{f}$ is fracture strain, $\boldsymbol{h}_{\boldsymbol{0}}$ initial sample thickness, $\boldsymbol{h}_{\boldsymbol{f}}$ sample thickness in the crack region, $\boldsymbol{d}^{*}$ is displacement at sample fracture and $\beta, \boldsymbol{x}, \boldsymbol{K}$ and $\boldsymbol{J}_{\boldsymbol{0}}$ are empirically determined constants.

There are two possibilities of $\varepsilon_{f}$ determination as can be seen from Eq. (4). The first is to determine the fracture strain by measurement of the sample thickness after fracture in the crack region according to Fig. 7. The second possibility is its determination from test records by using the displacement at fracture $\left(\boldsymbol{d}^{*}\right)$. Comparison of the fracture strain determined by both methods is shown in Fig. 8 where it can be seen that there is a linear trend between fracture strains $\varepsilon_{f}$ obtained by both methods. On the basis of this finding, it is concluded that $\varepsilon_{f}$ can be determined directly from the test records without the need for additional experimental effort. The fracture strains obtained from the graphs were used for further evaluations. 


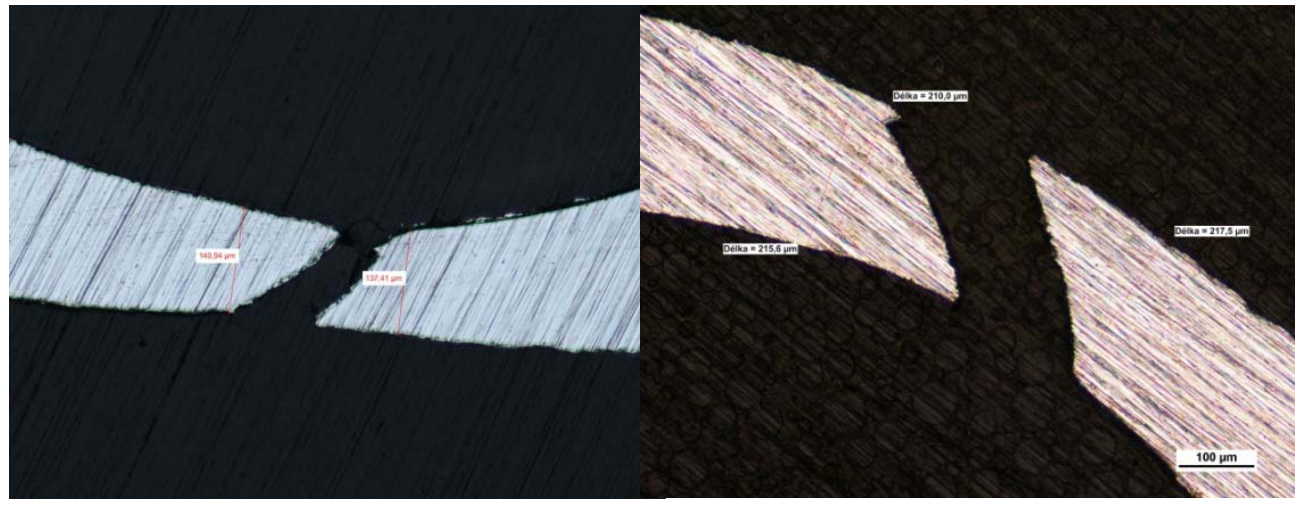

a) Steel $1-$ annealed at $500^{\circ} \mathrm{C}$

b) 34 CrNiMo6 - as delivered - longitudinal

Fig. 7. Determination of $\varepsilon_{f}$ on the basis of optical measurements

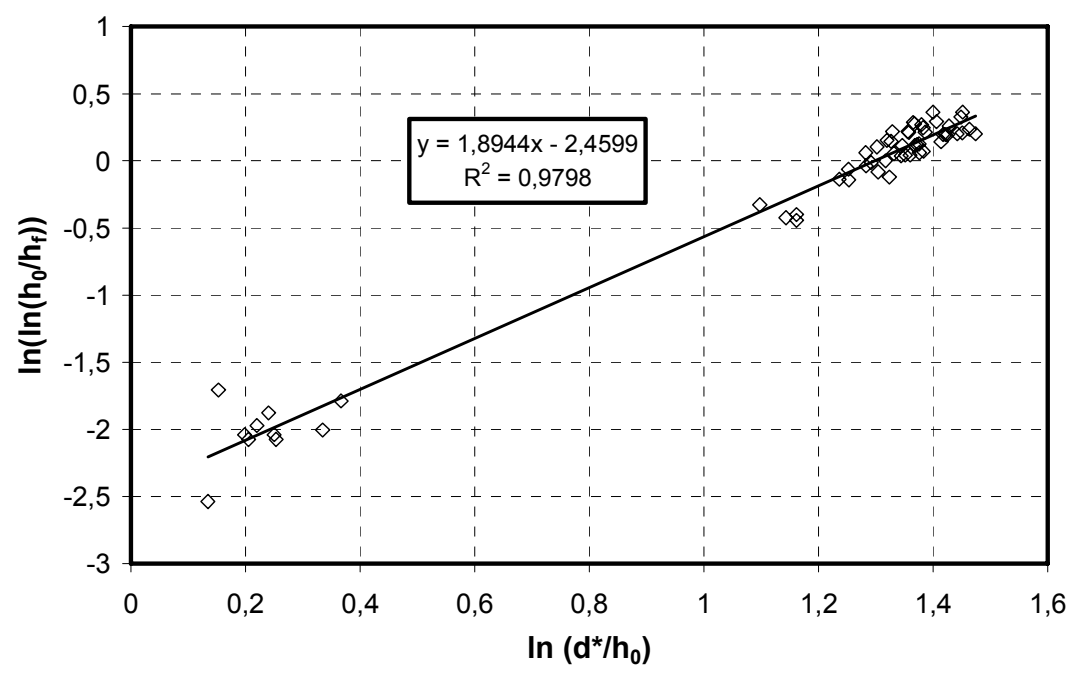

Fig. 8. Comparison of $\varepsilon_{f}$ determined from facture faces and from calculation

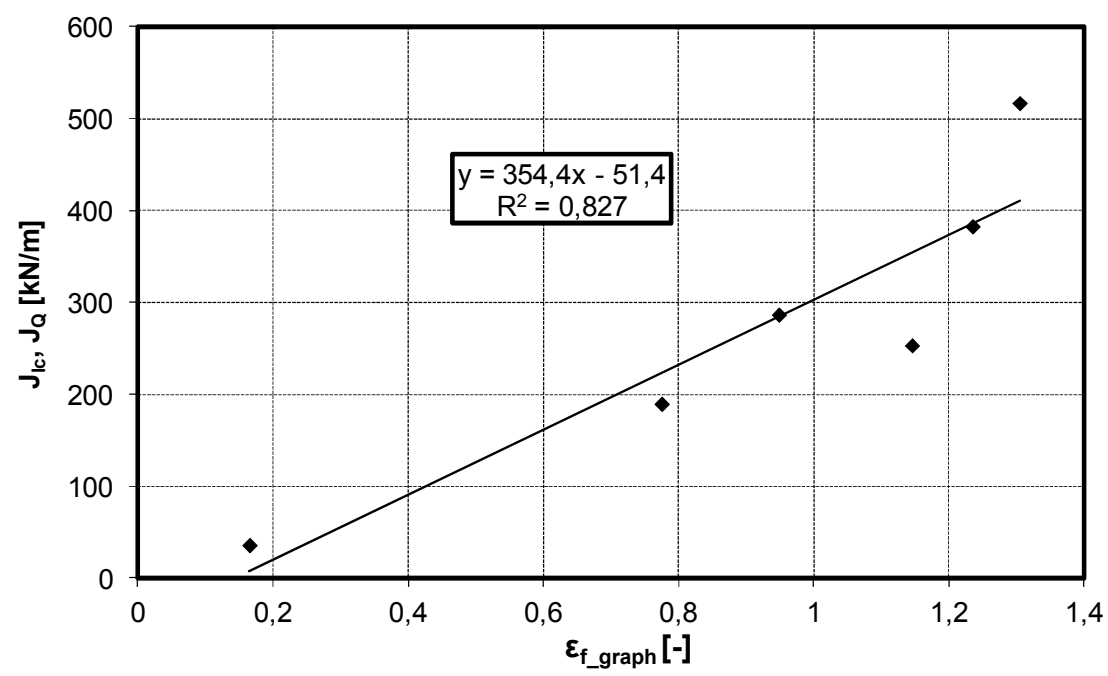

Fig. 9. Determination of correlation constants for fracture toughness determination

The values of the constants for the current materials in Eq. (3) were determined from Fig. 9.; $\boldsymbol{K}=354,4 \mathrm{kN} / \mathrm{m}$ and $\boldsymbol{J}_{\boldsymbol{0}}=51,4 \mathrm{kN} / \mathrm{m}$. The constants in Eq. (4) were determined iteratively by searching the best agreement between results of standard tests and SPT; $\beta=$ $0,111, \boldsymbol{x}=1,69$. 
The fracture toughness values obtained from SPT tests and from standard tests are summarized in Table 4. A graphical representation of the data is shown in Fig. 10 where $\pm 15 \%$ error boundaries are shown.

Table 4. Results of fracture toughness evaluation

\begin{tabular}{|c|c|c|c|c|c|c|}
\hline Material & State & $\begin{array}{c}\text { Temperature } \\
{ }^{\circ} \mathrm{C}\end{array}$ & $\begin{array}{l}\text { JIC_SPT }_{\text {IC_. }} \\
\text { kN.m }\end{array}$ & $\begin{array}{l}\mathbf{J}_{\mathrm{IC},} \mathrm{J}_{\mathrm{Q}} \\
\mathrm{kN} \cdot \mathrm{m}\end{array}$ & $\begin{array}{l}\text { K}_{\text {IC_SPT }} \\
\text { MPa.m }\end{array}$ & $\begin{array}{c}\mathbf{K}_{\mathrm{Ic}}, \mathbf{K}_{\mathrm{Q}} \\
\text { MPa.m }\end{array}$ \\
\hline \multirow{7}{*}{ Steel 1} & Original & 20 & ---- & ---- & 113,7 & 127,1 \\
\hline & Original & -20 & ---- & ---- & 115,5 & 105,5 \\
\hline & 250 & 20 & ---- & ---- & 120,3 & 112,6 \\
\hline & 350 & 20 & --- & ---- & 114,2 & 127,0 \\
\hline & 440 & 20 & 354,4 & 253,5 & 286,0 & 241,9 \\
\hline & 500 & 20 & 386,2 & 383 & 298,5 & 297,3 \\
\hline & 620 & 20 & 410,9 & 517 & 307,9 & 345,4 \\
\hline \multirow{3}{*}{ 34CrNiMo6 } & Long & 20 & 284,7 & 286,8 & 256,3 & 257,3 \\
\hline & Trans & 20 & 223,2 & 189,9 & 227,0 & 209,3 \\
\hline & Quenched & 20 & ---- & --- & 101,3 & 92,2 \\
\hline
\end{tabular}

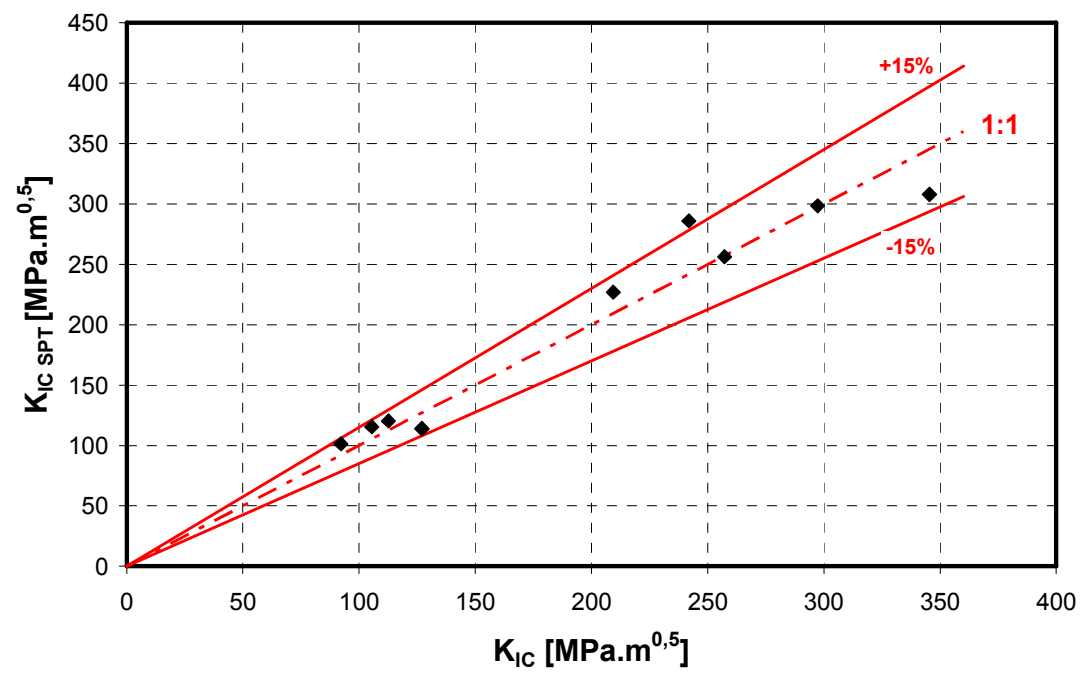

Fig. 10. Graphical summarization of fracture toughness evaluation results

\section{Discussion of Results}

Evaluation of the tensile test data shows very good agreement between the small punch test data and the results obtained by standard tensile tests. These results strongly support the application of small punch tests for tensile property evaluation for the steels investigated under all the conditions considered.

The fracture toughness tests of experimental material on the lower and the upper shelf regions were performed together with small punch tests. Separated evaluations were carried out for both regions.

In the lower shelf region, evaluation of fracture toughness from SPT was based on Eqs. (1) and (2). In this evaluation one constant has to be found only. The constant for the current data set was obtained and good agreement between reference values and SPT values was found.

In the case of stable crack extension behaviour is fracture toughness evaluated according to Eqs. (3) and (4) from SPT. In this case the evaluation is using fracture strain. The fracture strain can be determined on the basis of physical measurements of sample after the tests, or from obtained test records. Experimental measurement of the fracture strain requires additional effort, while direct evaluation from the graph is simple and can be automated. Analyze of current results pointed out possibility of the use of fracture strain 
determined from graph. With the use of this determination fracture toughness for the upper shelf behaviour was evaluated. Results of determined fracture toughness data are summarized in Fig. 10, where very good agreement of SPT based results with those obtained from standard tests is confirmed. This finding is very positive confirmation of the applicability of SPT to fracture toughness determination.

\section{Conclusions}

Small punch tests (SPT) applicability to material properties change evaluation was investigated here. Altogether, two materials in 10 states were investigated for sensitivity assessment of the SPT method. Tensile tests properties and fracture toughness properties were observed.

Tensile tests evaluation shown very good agreement between small punch test data and results obtained by standard tensile tests. These results prove possibility of application of small punch tests for tensile properties evaluation the material behaviour change description.

Fracture toughness tests of the materials investigated exhibited very good results in comparison with fracture toughness data from standard tests. The assessment of the SPT tests pointed out following results:

- Determination of lower shelf fracture toughness and upper shelf fracture toughness has to be done separately.

- In the case of upper shelf behaviour, where the evaluation is based on fracture strain, the fracture strain can be evaluated from SPT record directly without need for additional measurements.

- $\quad$ Very good agreement between reference values and SPT results is found.

SPT is potentially very powerful method in cases when limited amount of material is available e.g. for the residual life evaluation of in service components. Attention has to be paid if correct parameters and correct evaluation procedure is used for the material investigated.

\section{Acknowledgements}

This work was done within the work on the project "Ductile damage parameters identification for nuclear power plants - FR-TI2/279" sponsored by Ministry of Industry and Trade of The Czech Republic.

\section{References}

[1] DŽUGAN, J., KONOPÍK, P.: Evaluation of fracture toughness properties for low carbon steel in the brittle state by small punch test technique, Hutnické listy, 2010, Vol. LXIII, ISSN 0018-8069, ISBN 978-80-254-7994-0, p. 119-122.

[2] KONOPÍK, P., DŽUGAN, J.: Small punch test application to fracture toughness determination in the upper shelf region, Hutnické listy, 2010, Vol. LXIII, ISSN 0018-8069, ISBN 978-80-254-7994-0, p.123-127.

[3] WANG, Z.-X. et al.: Small punch testing for assessing the fracture properties of the reactor vessel steel with different thicknesses, Nuclear Engineering and Design, Volume 238, Issue 12, December 2008, p. 3186-3193

[4] MATOCHA, K., PURMENSKY, J.: Non destructive evaluation of mechanical characteristics of in-service components materials by small punch tests, NDT for Safety November 07-09, 2007, Prague, Czech Republic.

[5] Small punch test method for metallic materials, Part B: A code of practice for small punch testing for tensile and fracture behaviour, CWA 15627.

[6] SHINDO, Z., ZAMAGUCHI, Z., HORIGUCHI, K.: Small punch testing for determining 
the cryogenic fracture properties of 304 and 316 austenitic stainless steels in a high magnetic field, Cryogenics, Volume 44, Issue 11, November 2004, p. 789-792.

[7] BULLOCH, J. H.: A study concerning material fracture toughness and some small punch tests data for low alloy steels, Engineering failure analysis 11(2004), p. $635-653$.

[8] KUPCA, L., VACLAVKOVA, J.: Application of the small punch test methods for the mechanical properties evaluation, METAL 2001, 15-17.5.2001, Ostrava, Czech Republic.

[9] SAUCEDO-MUNOZ, M.L. et al.: Correlation between JIC and equivalent fracture strain determined by small-punch tests in JN1 JJ1 and JK2 austenitic stainless steels, Cryogenics 41 (2001), p. 913-719.

[10] HA, J. S., FLEURY, E.: Small Punch Tests to Estimate the Mechanical Properties of Steels for Steam Power Plant: II. Fracture Toughness. International Journal of Pressure Vessels and Piping 75 (1998) p. 707-713 